\title{
THEORETICAL EVALUATION OF MASS TRANSFER COEFFICIENTS IN SOLUTION CRYSTALLIZATION
}

\author{
J.M.F. SILVA ${ }^{1}$, J. P. SILVA ${ }^{1}$, T. P. C. SOUZA ${ }^{1}$, C.P.G. LIRA $^{1}$ e B. F. SANTOS ${ }^{1}$ \\ ${ }^{1}$ Federal University of Pernambuco (UFPE), Department of Chemical Engineering, \\ Av Arthur de Sá, S/N, CEP 50740-521 - Recife - PE - Brazil \\ E-mail para contato: jmfs5@yahoo.com.br
}

\begin{abstract}
Mass transfer is an important phenomenon in most chemical processes and studies involving determination of mass transfer coefficients are necessary for a better estimation of equipment performance. Solid-liquid mass transfer coefficients in stirred systems have received substantial attention in the past due to their practical applications. In contrast, little information is available on solid-liquid mass transfer in crystallization systems, despite the importance of crystallization. In this work, an expression for the mass transfer coefficients in solution crystallization, has been developed based on the Stefan problem formulation. The model is able to predict a finite mass transfer coefficient when the layer thickness vanishes. The obtained mass transfer coefficients agree with previously reported experimental data.
\end{abstract}

\section{INTRODUCTION}

Crystallization is a widely used operation in industrial processes. Relevant examples are found in pharmaceutical, high-performance polymer and electronic industries (Chen et al., 2011; Miozzo et al., 2010; Huang et al., 2012 and Su et al., 2013). Despite its importance, very little is known about solid-liquid mass transfer coefficients in crystallization. Several experimental works for the determination of mass transfer coefficients in crystallization have been reported (Martins and Rocha, 2006; Van der Gun et al., 2005; Sahin et al., 2004; Louhi-Kultanen et al., 2001). On the other hand, mass transfer coefficients in gas-liquid stirred systems have received substantial attention in the past, and many correlations can be found in the literature (Nienov, 1992). Due to the difficulty in measuring the coefficient of mass transfer in the crystallization process, the work of Zhao et al.( 2012) show a new method to calculate mass transfer flux during the crystal growth without the knowledge of the mass transfer coefficient. In the present work, a theoretical expression for the mass transfer in solution crystallization based on the Stefan problem model, has been developed, and a finite mass transfer coefficient is obtained when layer thickness vanishes.

Stefan problems arise when domains of boundary conditions of partial differential equations are not known. They are included, instead, as part of the equation solution scheme. Such problems are known as moving boundary problems. In these cases, the boundary position depends on time and space. Moving boundary problems are frequently called Stefan problems, with reference to the work of Stefan in that area. The first work that can be associated with the mathematical problem of moving boundaries is that proposed by Clapeyron and Lamé (1831). They determined the thickness of a solid 
generated by the cooling of a liquid. Stefan (1889) solved a more general problem for the growth of a freezing boundary.

\section{MATHEMATICAL MODELING}

Generally, diffusion through film thickness is used for correlating data in industrial crystallization processes. The first investigations (Berthoud, 1912; Valeton, 1923) suggested that there are two steps in mass deposition during crystallization. The first one is a diffusive process, whereby the solute is transported from a liquid phase bulk to a solid surface, followed by a first order "reaction" when solute molecules arrange themselves onto crystal lattice. In practice, as interfacial concentrations are difficult to measure, it is better to consider an "overall" concentration driving force, $\left(C_{A}-C_{A}^{*}\right)$, which can be more easily measured. A general Eq. (1) for crystallization based on this overall driving force can be written as (Mullin, 1972)

$$
\frac{d m_{A}}{d t}=k_{G A} A\left(C_{A}-C_{A}^{*}\right)^{n}
$$

Where $\mathrm{k}_{\mathrm{GA}}$ is an overall crystal growth coefficient. The exponent $\mathrm{n}$ is usually referred to as "order" of crystal growth process. Use of this term should not be confused with its more conventional use in chemical kinetics. In crystallization, the exponent, which is applied to a concentration difference, has no fundamental significance and does not indicate the number of elementary species involved in the growth process.

For $n=1$ the surface reaction is a first-order process. Therefore:

$$
k_{G}=\frac{k_{d} k_{r}}{k_{d}+k_{r}}
$$

Where $\mathrm{k}_{\mathrm{d}}$ is the diffusive mass transfer coefficient and $\mathrm{kr}$ is the constant surface reaction rate .

In cases of extremely fast surface reaction, that is, for high $\mathrm{kr}$, then $\mathrm{k}_{\mathrm{G}} \cong \mathrm{k}_{\mathrm{d}}$ and the crystallization process is controlled by diffusion on film thickness. Similarly, if kd is high the diffusional resistance is low implying $\mathrm{k}_{\mathrm{G}} \cong \mathrm{k}_{\mathrm{r}}$. Inthis case, the process is controlled by surface reaction.

An expression can be obtained for the mass transfer coefficient using Eq. (1) considering the linear form $(\mathrm{n}=1)$

$$
\frac{d L}{d t}=\frac{k_{G}}{C_{0}}\left(C_{A S S}-C_{A S}\right)
$$

Where $\mathrm{C}_{0}$ it is the crystal molar concentration.

Silva et al. (2006) solved the Stefan problem applied to a crystallization process, in which the 
mass transfer is the most important phenomenon. Now, consider the schematic drawing of the crystal shown in Figure 1.

In the present work $\zeta$ is defined in the following as follows:

$$
\zeta=\frac{X-\mathrm{L}_{\mathrm{C}}-\varepsilon}{L_{C}}
$$

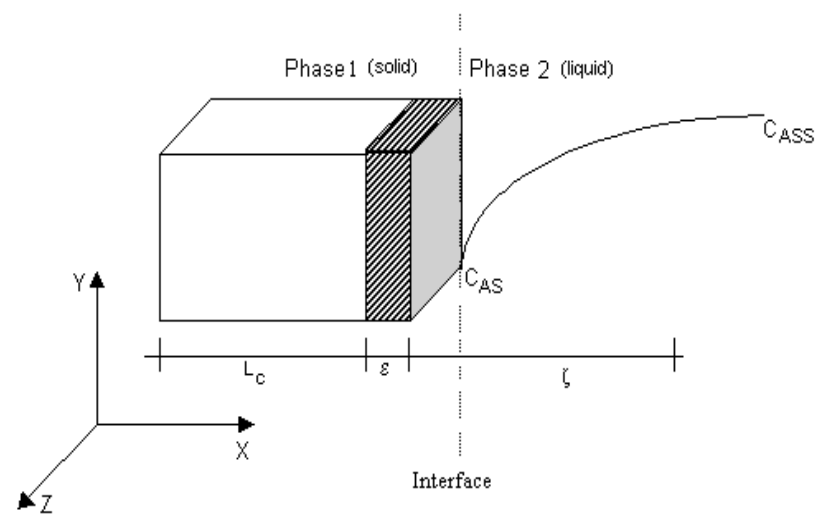

Fig.1 Schematic drawing of the crystal growth

It should be observed, according to Figure 1, that $\zeta$ Lc is the thickness of the film for mass transfer around the crystal. As the change in the number of moles of the crystal per unit of time is equal to the diffusive rate of A that arrives at the crystal surface, the Eq. (5) can be obtained:

$$
\begin{aligned}
& \frac{\mathrm{d} \zeta}{\mathrm{dt}}=\left.\gamma \frac{\partial \mathrm{U}}{\partial \zeta}\right|_{\xi=\xi^{\prime}} \\
& \gamma=\frac{D_{A B}\left(C_{A S S}-C_{A S}\right)}{C_{0} L_{c}^{2}\left(1-X_{A}\right)}
\end{aligned}
$$

Notice that the function had been obtained previously in Silva et al.,(2006), whose value is:

$$
\begin{aligned}
& U(\zeta, t)=\operatorname{erf}\left(\frac{\zeta}{2 a \sqrt{t}}\right) \\
& a^{2}=\frac{D_{A B}}{L_{c}^{2}}
\end{aligned}
$$


Where $\zeta$ is the dimensionless length, DAB is diffusivity, $\mathrm{C} 0$ is the crystal molar concentration and Lc is the crystal critical radius. For most solutions the degree of supersaturation (CASS - CAS) is relatively low (Mersmann, 1988) and for low supersaturation, as how it was previously shown in Silva et al. (2006) $\gamma$ can be approximated by

$$
\gamma=\frac{C_{T} D_{A B}\left(C_{A S S}-C_{A S}\right)}{C_{0} L_{c}^{2}\left(C_{T}-C_{A S}\right)}
$$

In this way, after substitution of Eq. (6), (7), (8) and (9) into Eq. (5), the following expression is obtained,

$$
\frac{d \zeta}{d t}=\frac{D_{A B} C_{T}\left(C_{A S S}-C_{A S}\right) \exp \left(-\frac{\zeta^{2}}{4 a^{2} t}\right)}{C_{0} L_{c}\left(C_{T}-C_{A S}\right)}
$$

Multiplying Eq. (10) by the crystal critical radius, Lc, and comparing the result to Eq. (3), the following expression is obtained for the mass transfer coefficient.

$$
K_{G}=\frac{C_{T} e^{-\left(\frac{\zeta^{2} L_{c}^{2}}{4 D_{A B} t}\right)}}{\left(C_{T}-C_{A S}\right)} \sqrt{\frac{D_{A B}}{\pi t}}
$$

In a way similar to the penetration theory (Bird et al., 1960), the mass transfer coefficient is proportional to $\sqrt{D_{A B} / \pi t}$. However, in the present case, dependence on time also includes an exponential term. It should be noted that as time increases, the influence of the exponential term decreases and the dependence on time tends to approach that predicted by penetration theory.

In Eq. (11), the term $\zeta$ Lc represents film thickness around crystal surface. Mullin (1972) reported that film thickness varies from (20 to 150) $\mu \mathrm{m}$, measured on a stationary crystal in stagnant aqueous solutions. He also mentioned, however, that in the experimental data reported by Marc (1908, 1909a, 1909b, 1910), film thickness decreased significantly and tended to zero for vigorously stirred solutions. This kind of result implies an almost infinite rate of crystal growth in vigorously agitated systems. Berthoud (1912) and Valeton (1923) suggested modifications to the diffusion theory of crystallization. According to them, there are two steps in the crystallization process: the first one is the mass transport by diffusion of solute molecules from liquid phase bulk to solid surface, and the second one is a first-order "reaction" step when solute molecules arrange themselves onto a crystal lattice. It can be observed from Eq. (11) that mass transfer coefficients decrease as film thickness increases and, at the limiting case of zero film thickness, the mass transfer coefficient tend to have finite values. In all cases the mass transfer coefficient values decrease as a function of time. 


\section{RESULTS AND DISCUSSION}

The following values for the model variables were considered: $\mathrm{CT}=26.13 \mathrm{kmol} / \mathrm{m} 3 ; \mathrm{C} 0=$ $4.64 \mathrm{kmol} / \mathrm{m} 3 ; \mathrm{CAS}=3.48 \mathrm{kmol} / \mathrm{m} 3 ; \mathrm{DAB}=(0.250,0.314,0.355) \times 10-9 \mathrm{~m} 2 / \mathrm{s}$ and boundary layer thickness $\zeta \mathrm{Lc}=10 \mu \mathrm{m}$. These values were selected based on properties of sucrose solutions under crystallization conditions at $20^{\circ} \mathrm{C}$ (Norrish, 1967). Values for diffusivity of sucrose in water were taken from Washburn (1929) and a relative supersaturation of 7\% (Norrish, 1967), which corresponds to CASS $=2.82 \mathrm{kmol} / \mathrm{m} 3$, was used in most cases. Dynamic behavior of mass transfer coefficient is shown in Figure 2.

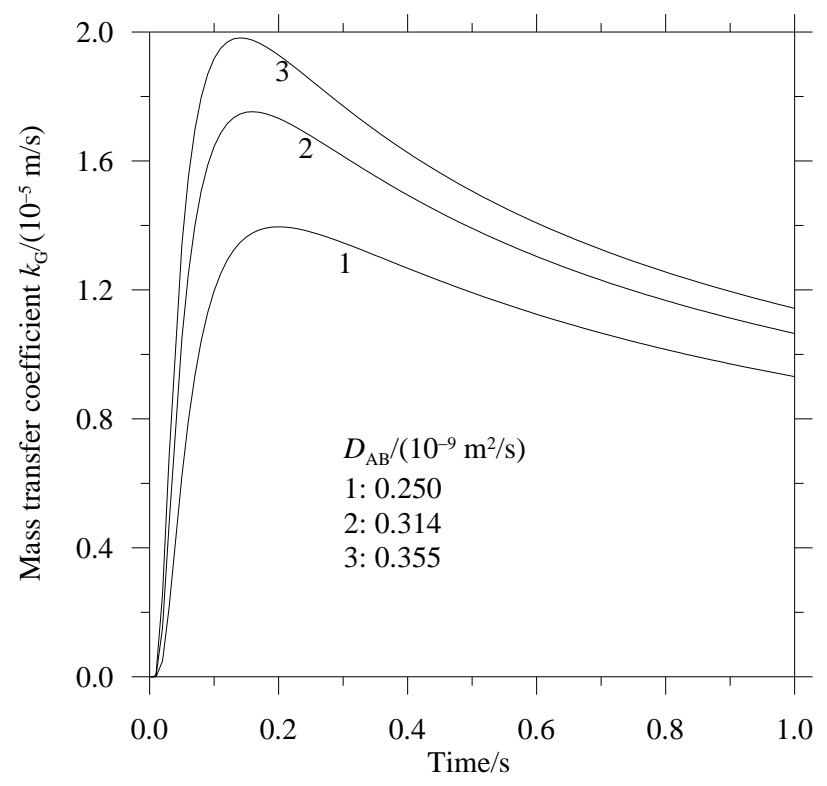

Fig.2 Dynamic behavior of mass transfer coefficient for crystallization case study.

It can be observed that the mass transfer coefficient dynamic is very fast (a fraction of second). It can also be observed that after a maximum value is reached very soon, it decreases for fixes at a constant value. As expected, a larger value in the diffusivity provides a larger value in the mass transfer coefficient. This fact is in agreement with the rate of crystal growth behavior presented in a previous work (Silva et al., 2006), where the initial rate was higher, and decreased more than quickly to a smaller value. The time at which the mass transfer coefficient reaches a maximum value it is given by

$$
t_{\max }=\frac{\zeta^{2} L_{c}^{2}}{2 D_{A B}}
$$

As expected, Eq. (12) gives an extremely small time lapse.

Figure 3 (A) illustrates the mass transfer coefficient for three boundary layer values of $(0,5$ and 10) $\mu \mathrm{m}$. As expected, the smaller the boundary layer thickness, the higher the mass transfer 
coefficient is obtained. This fact shows that larger boundary layers slow down the crystallization process.
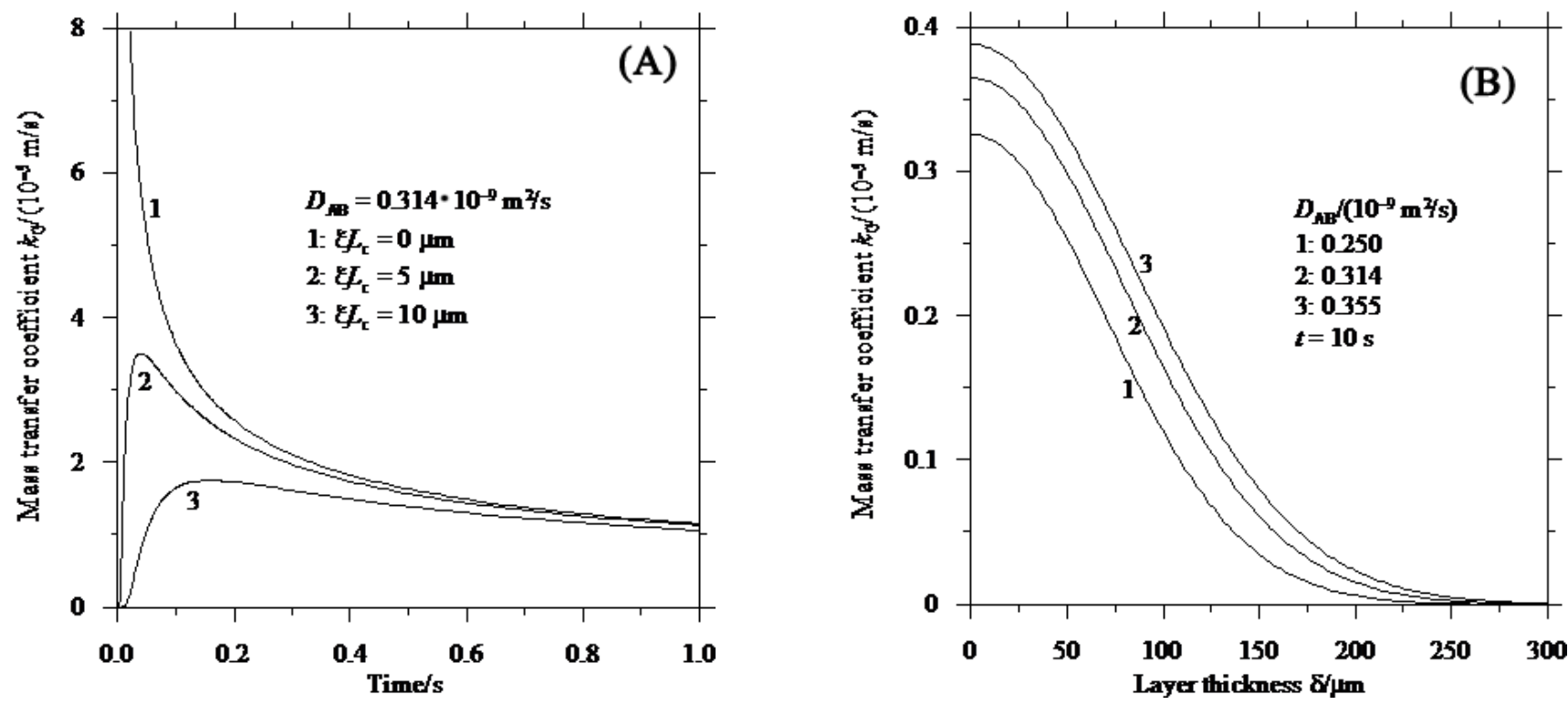

Fig. 3 (A) Mass transfer coefficient dynamic behavior in crystallization process for different limiting layer thickness. (B) Mass transfer coefficient as a function of limiting layer thickness.

For the same parameter values as in the previous illustration, Figure 4 shows mass transfer coefficients as a function of limiting layer thickness.

Figure 3 (B) also demonstrates the mass transfer coefficient dependence on system hydrodynamics. It can also be observed in Figure 3 (B) that at zero thickness a finite value was predicted for the mass transfer coefficient, as experimentally expected. Finally, Figure 3 (B) shows that the mass transfer coefficient vanishes for any limiting layer values higher than those determined by Marc (1908, 1909 and 1910), that is, (20 to 150) $\mu \mathrm{m}$.

\section{CONCLUSIONS}

A mathematical model has been developed to predict mass transfer coefficients in solid-liquid systems. This model is limited to the effect of mass transfer growth phenomena. It has been shown that a finite mass transfer coefficient is obtained for zero thickness limiting layer. This fact was observed experimentally by Marc (1908, 1909 and 1910) showing that the diffusion through film concept can explain crystal growth. The mass transfer coefficient of the crystal reaches a maximum, then decreases and reaches a lower constant value. Boundary layer thickness causes the mass transfer coefficient to decrease, reaching zero around $60 \mu \mathrm{m}$ relative to the process variables used in the case study. The stagnant effective film thickness obtained is of the same order of magnitude as those determined experimentally by Marc (1908, 1909 and 1910). 


\section{NOTATION}

A crystal interfacial area perpendicular to diffusive flux $\left(\mathrm{m}^{2}\right)$

$C_{0} \quad$ crystal molar concentration $\left(\mathrm{kmol} / \mathrm{m}^{3}\right)$

$C_{\mathrm{A}} \quad$ solute A molar concentration $\left(\mathrm{kmol} / \mathrm{m}^{3}\right)$

$C_{A}^{*} \quad$ solute A molar concentration at equilibrium $\left(\mathrm{kmol} / \mathrm{m}^{3}\right)$

$C_{\mathrm{T}} \quad$ solution molar concentration $\left(\mathrm{kmol} / \mathrm{m}^{3}\right)$

$C_{\mathrm{ASS}} \quad$ solute bulk concentration $\left(\mathrm{kmol} / \mathrm{m}^{3}\right)$

$C_{\mathrm{AS}} \quad$ solute interfacial concentration $\left(\mathrm{kmol} / \mathrm{m}^{3}\right)$

$D_{\mathrm{AB}} \quad$ diffusivity $\left(\mathrm{m}^{2} / \mathrm{s}\right)$

$\bar{G} \quad$ average crystal growth rate (m/s)

$k_{\mathrm{G}} \quad$ mass transfer coefficient $(\mathrm{m} / \mathrm{s})$

$k_{\mathrm{GA}} \quad$ overall crystal growth coefficient (m/s)

$L_{\mathrm{c}} \quad$ crystal critical radius $(\mu \mathrm{m})$

$\mathrm{N}$ number of moles

$n \quad$ crystal growth order

$Q \quad$ crystallizer flow rate $\left(\mathrm{m}^{3} / \mathrm{s}\right)$

$t \quad$ time (s)

$t_{\max } \quad$ time at mass transfer coefficient maximum (s)

$U$ dimensionless concentration

$X_{\mathrm{A}} \quad$ solute mole fraction

$\delta \quad$ effective stagnant film thickness $(\mu \mathrm{m})$

$\delta_{\mathrm{h}} \quad$ hydrodynamic boundary layer $(\mu \mathrm{m})$

$\delta_{\mathrm{m}} \quad$ diffusion layer $(\mu \mathrm{m})$

$\tau \quad$ residence time (s)

$\zeta \quad$ dimensionless length

\section{REFERENCES}

Berthoud, A. Theorie de la formation des faces d'um crystal, J. Chim. Phys., Vol. 10, p-624, (1912).

Bird, R. B. Stewart, W. E. and Lightfoot, E. N., Transport Phenomena, 2nd ed., John Wiley \& Sons, New York (2007).

Clapeyron, P.B. and G.Lamé, memory on the solidification by cooling of a solid sphere (in French), ann. Chem.Phys.,47, 250-256, 1831.

Chen J., Sarma B., Evans J. M. B., Myerson A. S., Pharmaceutical Crystallization. Crystal Growth \& Design, 11, p887-895, (2011).

Louhi-Kultanen M., Kallas .J, Partanen J., Sha Z., Oinas P., Palosaari S., The influence of multicomponent diffusion on crystal growth in electrolyte solutions, Chemical Engineering Science, 56 (11): 3505-3515, (2001).

Martins P. M and Rocha, F., The role of diffusional resistance on crystal growth: Interpretation of dissolution and growth rate data, Chemical Engineering Science 61 (17): 5686-5695 SEP (2006). 
Marc, R., über die kristallisation aus wässerrigen lösungen, Z. Phys. Chem., vol. 61, 385; vol-67, 470; vol-73, 685, (1908, 1909 and 1910).

Su J., Yang G., Zhou T., Gao X., Wang K., Fu Q., Enhanced crystallization behaviors of poly(ethylene terephthalate) via adding expanded graphite and poly(ethylene glycol), Colloid and Polymer Science, v291 i4, p911-917, (2013).

Mersmann, A., Design of Crystallizers, Chem. Eng. Process., 23, 213-228, (1988).

Miozzo, L., Horowitz G., Yassar A., Surface engineering for high performance organic electronic devices: the chemical approach Journal of Materials Chemistry, v 20, 2513 (2010)

Mullin, J. W., Crystallization, 2nd ed. Butterworths, London, (1972).

Nienov A. W., The Mixer as a reactor: liquid/solids systems. In Harnby N., M. F. Edwards and A.W. Nienov. Mixing in the process industries, 2nd edition, Butteworth \& Co, London, UK, (1992).

Norrish, R. S.,Selected Tables of physical properties of sugar solutions, Scientific and Technical Surveys, The British Food Manufacturing Industries Research Association, Number 51, (1967).

Sahin O, Ozdemir M, Genli N., Effect of impurities on crystal growth rate of ammonium pentaborate, Journal of Crystal Growth, 260 (1-2): 223-231,(2004).

Silva, José Marcos F.; Lopes, Carlos E.; Antonio J. A. Meirelles and Wolf-Maciel, M. R., Stefan's problem applied to solution crystallization, Journal of Chemical Engineering of Japan, Vol. 39, No. 9, pp. 940-947, (2006).

Huang W., Yu J., Yu X., Li Y., Zeng H., Performance enhancement of organic thin-film transistors with improved copper phthalocyanine crystallization by inserting ultrathin pentacene buffer. Thin Solid Films, v520 i21 p6677-6680, (2012).

Stefan, J., On some problems of the heat transfer theory (in Germain),Wien Akad. Mat. Natur.,98, 616-634, 1889.

Valeton, J.J.P., Wachstum und auflÖsung der kristalle, Z. Kristallogr., vol.-59, p-135, (1923).

Van der Gun, M. A., Bruinsma, O. S. L., Jansens PJ. Purification of polycrystalline $\varepsilon$-caprolactam particles, Chemical Engineering Science, 60 (1): 201-211, (2005).

Washburn, E.W., International critical tables of numerical data, physics, chemistry and technology Ed. by Edward W. Washburn, McGraw-Hill, New York, Vol. 5, p. 63, (1929).

Zhao J., Miao H., Duan L., Kang Q., He L. H., The mass transfer process and the growth rate of $\mathrm{NaCl}$ crystal growth by evaporation based on temporal phase evaluation, Opt. Lasers Eng.50(4), 540-546 (2012). 